\title{
Unmet Medical Needs in Ulcerative Colitis: An Expert Group Consensus
}

\author{
Silvio Danese ${ }^{a} \quad$ Matthieu Allez ${ }^{b}$ Ad A. van Bodegraven ${ }^{c}$ Iris Dotan ${ }^{d, e}$ \\ Javier P. Gisbert ${ }^{f}$ Ailsa Hart ${ }^{g}$ Peter L. Lakatos ${ }^{\text {h, }}{ }^{i}$ Fernando Magro $^{j}$ \\ Laurent Peyrin-Biroulet ${ }^{k}$ Stefan Schreiber ${ }^{l}$ Dino Tarabar ${ }^{m}$ Stephan Vavrickan \\ Jonas Halfvarson $^{\circ}$ Séverine Vermeire ${ }^{p}$

\begin{abstract}
${ }^{a}$ Humanitas Research Hospital, Milan, Italy; ${ }^{b}$ Department of Gastroenterology and Hepatology, Hôpital Saint-Louis, Paris, France; ' Zuyderland Medical Center, Sittard and VU University Medical Center, Amsterdam, The Netherlands;

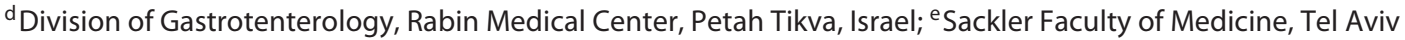
University, Tel Aviv, Israel; ${ }^{f}$ Hospital Universitario de La Princesa, Instituto de Investigación Sanitaria Princesa (IIS-IP), Universidad Autónoma de Madrid, Centro de Investigación Biomédica en Red de Enfermedades Hepáticas y Digestivas (CIBEREHD), Madrid, Spain; ${ }^{9}$ IBD Unit, St. Mark's Hospital, London, UK; ${ }^{\text {h} M c G i l l ~ U n i v e r s i t y, ~ M U H C, ~ M o n t r e a l ~ G e n e r a l ~}$ Hospital, Montreal, QC, Canada; 'Department of Medicine, Semmelweis University, Budapest, Hungary; ${ }^{j}$ University of Porto and Centro Hospitalar São João, Porto, Portugal; ' Nancy University Hospital and Université de Lorraine, Nancy, France; 'University Hospital Schleswig-Holstein, Kiel, Germany; ${ }^{m}$ Clinic for Gastroenterology and Hepatology, Military Medical Academy, Belgrade, Serbia; ${ }^{n}$ Division of Gastroenterology, Stadtspital Triemli, Zurich, Switzerland;

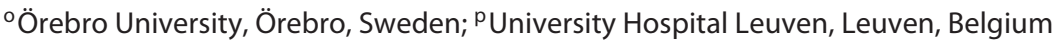

\section{Keywords}

Consensus panel · Delphi process · Systematic literature review · Ulcerative colitis · Unmet needs

\begin{abstract}
Background: The authors aimed to conduct an extensive literature review and consensus meeting to identify unmet needs in ulcerative colitis (UC) and ways to overcome them. $\mathrm{UC}$ is a relapsing and remitting inflammatory bowel disease with varied, and changing, incidence rates worldwide. UC has an unpredictable disease course and is associated with a high health economic burden. During 2016 and 2017, a panel of experts was convened to identify, discuss and address areas of unmet need in UC. Methods: PubMed and Cochrane Library databases were searched for relevant articles describing studies performed in patients with UC. These find-
\end{abstract}

\section{KARGER}

(c) 2019 S. Karger AG, Basel

E-Mail karger@karger.com

www.karger.com/ddi ings were used to generate a set of statements relating to unmet needs in UC. Consensus on these statements was then sought from a panel of 9 expert gastroenterologists using a modified Delphi review process that consisted of anonymous surveys followed by live meetings. Results: In 2 literature reviews, over 5,000 unique records were identified and a total of 138 articles were fully reviewed. These were used to consider 26 areas of unmet need, which were explored in 2 face-to-face meetings, in which the statements were debated and amended, resulting in consensus on 30 final statements. The unmet needs identified were categorised into 7 areas: impact of UC on patients' daily life; importance of early diagnosis and treatment; drawbacks of existing treat-

Séverine Vermeire

University Hospital Leuven

KU Leuven, UZ Herestraat 49

BE-3000 Leuven (Belgium)

E-Mail severine.vermeire@uzleuven.be

Jonas Halfvarson

Department of Gastroenterology

Faculty of Medicine and Health, Örebro University

SE-70182 Örebro (Sweden)

E-Mail jonas.halfvarson@ regionorebrolan.se 
ments; urgent need for new treatments; and disease-, practice- or patient-focused unmet needs. Conclusions: These expert group meetings found a number of areas of unmet needs in UC, which is an important first step in tackling them in the future. Future research and development should be focused in these areas for the management of patients with UC.

(c) 2019 S. Karger AG, Basel

Ulcerative colitis (UC) is a chronic inflammatory condition causing continuous mucosal inflammation of the colon, affecting the rectum and the colon to a variable extent [1]. UC primarily presents in late adolescence/early adulthood and is characterised by a remitting and relapsing course [1]. The cardinal symptoms of UC are bloody diarrhoea, urgency and tenesmus; lower abdominal pain may also occur [2]. In some patients, the condition may markedly impact health-related quality of life (HRQoL) [3].

Complete remission of UC is defined as clinical as well as endoscopic remission, with macroscopic healing of the mucosa [4]. Mucosal healing is an important predictor of long-term outcomes of treatment [4].

5-Aminosalicylic acid (5-ASA) may be used to induce remission in mild-to-moderate UC [5]. In patients who fail to respond to 5-ASA and those with more severe disease, corticosteroids may be an option [6]. For nonresponders to corticosteroids treatment options include infliximab, ciclosporin, tacrolimus or surgery [5]. Thiopurines (azathioprine or mercaptopurine) may be useful in patients with corticosteroid-dependent disease [6]. 5-ASA may successfully maintain remission in responders to this agent, whereas remission induced by corticosteroids should be maintained by 5-ASA or, when clinically necessary, a thiopurine derivative [4]. Tumour necrosis factor (TNF) inhibitors, alone [7-10] or in combination with thiopurines [11], or the anti-integrin vedolizumab [12] may be used to induce and maintain remission in patients who are refractory to the above approaches. Patients who do not initially respond, or lose response, to a TNF inhibitor or vedolizumab may be switched to a different drug with another mechanism of action (swap) or the same target (switch) [4]. Surgery may be considered in a number of difficult clinical scenarios [5]. Reconstructive surgery with ileoanal pouch anastomosis is the surgical procedure of choice performed in patients with intractable disease or its complications. While usually associated with improvement in QoL, ileoanal pouch anastomosis may also impart substantial morbidity such as pouchitis and the poten- tial for pouch failure in approximately $5 \%$ of patients $[13,14]$.

Despite considerable advances in the knowledge of UC and the availability of a range of treatment options for the many clinical presentations of this greatly heterogeneous condition, in practice, gaining a satisfactory outcome for all patients remains elusive. The extent of unmet need in UC patients who exhibit an inadequate response, lose response or cannot tolerate available treatments is not widely understood [15].

There are areas of unmet need beyond those relating to improving treatment and achieving remission. A high incidence of UC in many European countries, North America, Australia and New Zealand [16] results in a high cost burden associated with the disease. While rising costs of medication may coincide with a reduction in costs associated with hospital admissions and surgery, the overall cost burden is high. One estimate places the annual cost of treating UC to healthcare systems across Europe at EUR 4.6-5.6 billion [17].

UC has an unpredictable natural history. The unpredictability of the disease and the lack of robust predictive biomarkers at UC onset strongly affect patient-reported outcomes (PROs) and the impact of the disease [18]. Current standards of care stratify patients by their disease extent, severity and response to treatment according to a "step-up" approach that begins with the least toxic treatments first [18-20].

Much of the literature emphasises positive disease outcomes, often related to the meeting of pre-defined study criteria. Such reports provide valid and useful data, but may fail to address areas of unmet need. Defining those unmet needs that exist in the care of patients with UC is an important step towards the development of strategies and allocation of resources to overcome them and optimise patient quality-of-life and quality-of-care.

Against this backdrop of unmet medical needs in the management of UC, as well as increasing prevalence, high health-economic burden and unpredictable disease course, a group of 14 gastroenterologists met to define, characterise and prioritise unmet needs in the management of UC. Based upon a systematic review of recent scientific literature, and using a modified Delphi process, the panel identified and agreed 18 unmet needs consensus statements. In addition to these statements, the panel proposed 11 additional areas of unmet need that fell outside of the scope of that meeting (Table 1) regarding the natural history of $\mathrm{UC}$, current practice in the treatment of UC, and patients' views on the management of UC. Based on these proposed additional un- 
Table 1. Preliminary statements and initial survey results

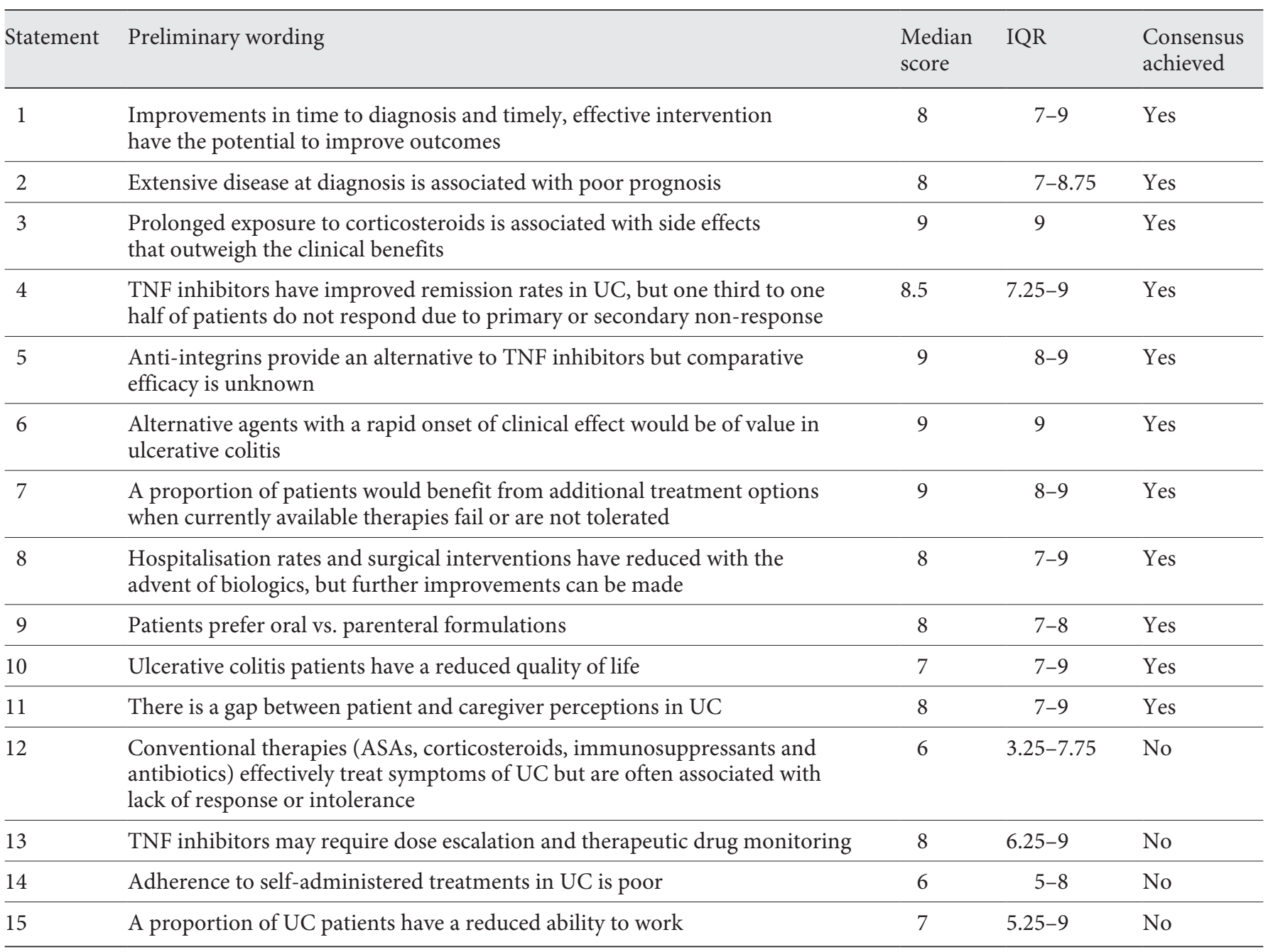

ASAs, aminosalicylic acids; IQR, interquartile range; TNF, tumour necrosis factor; UC, ulcerative colitis.

met needs, a second panel was convened in April 2017. The aim of this meeting was to, based on a new review of the literature, define, characterise and prioritise these 11 , and any additional relevant, unmet needs. The consensus-building process and conclusions of the $2 \mathrm{Un}$ met Needs in UC Expert Panel meetings are presented herein.

\section{Methods}

Unmet Medical Needs in UC

Literature Review

To investigate unmet needs in the treatment of UC, extensive literature reviews were performed. PubMed and Cochrane Library databases were searched for references published since
January 1, 2006 and May 2016 (however, important articles published later could be included during panel discussion - see below). Articles were restricted to English language publications and studies conducted in humans. Searches were performed in the format "UC AND secondary term". Secondary search terms included drug names and drug classes used in the treatment of UC (online suppl. Table 1, see www.karger.com/ doi/10.1159/000496739) and a list of relevant terms extracted from a recent systematic review by Linstone et al. [21] supplemented by the panel's personal experiences. Titles or abstracts were reviewed for relevance; publications were then screened for the following exclusion criteria: findings superseded by newer data; small study (<40 participants); single-centre studies; paediatric patients; not specifically investigating UC; or objective not aligned with the present search.

The results of the literature review were used to generate a preliminary set of statements that formed the basis of the questionnaire for the first round of the Delphi process. 
Table 2. Search terms utilised in the three separate literature searches

\begin{tabular}{|c|c|c|c|}
\hline \multirow{2}{*}{$\begin{array}{l}\text { Primary search } \\
\text { term }\end{array}$} & \multicolumn{3}{|c|}{ Secondary search terms } \\
\hline & From initial unmet needs statements & From refined unmet needs statements & Additional \\
\hline \multirow[t]{16}{*}{ UC } & Unmet need & Real world data & Steroid free response \\
\hline & Patient preference & Real world evidence & Endoscopic remission \\
\hline & Quality of life & Patient perspective & Histologic remission \\
\hline & FDA & Employment & Sustained remission \\
\hline & $\mathrm{PRO}$ & Absenteeism & Sustained response \\
\hline & Empowerment & Steroid-free remission & Clinical remission \\
\hline & Strategy & Mucosal healing & Treatment decision making \\
\hline & Treatment & Loss of response & Clinical decision making \\
\hline & Treatment guideline & Prognostic biomarkers & Course of disease \\
\hline & & Therapeutic biomarkers & Nature of disease \\
\hline & & Coping behaviour & DMAID \\
\hline & & Adaptation & Disease modifying \\
\hline & & Clinical practice & Natural history \\
\hline & & Long term remission & \\
\hline & & Clinical trial & \\
\hline & & Effectiveness & \\
\hline
\end{tabular}

DMAID, disease-modifying anti-inflammatory bowel disease drug; FDA, food and drug administration; PRO, patient-reported outcomes; UC, ulcerative colitis.

\section{Survey Participants}

The expert panel comprised 14 gastroenterologists with expertise in IBD from 13 European countries. All members of the panel participated in the Delphi survey.

\section{Delphi Process}

The Delphi method was developed to enable the exploration of complex problems through structured group communication [21]. It is an evidence-based approach that allows a group of individuals to explore issues surrounding a problem, establishing the advantages and disadvantages of different arguments, through the use of surveys and a final live meeting [22]. The process involves the formation of a steering committee responsible for identifying issues surrounding the problem in question, development of relevant survey questions and recruitment of a panel of experts to participate anonymously in the survey. In the present case, 1 round of anonymous completion of the survey was followed by a live meeting during which individual survey responses remained anonymous to preserve objectivity.

In round 1, an anonymous questionnaire invited respondents to score each of the preliminary statements derived from the literature review results on a 9-point Likert scale (ranging from 1, strongly disagree to 9, strongly agree). Then, median scores and interquartile ranges (IQR) from the group were calculated for each statement: an IQR 7 and above represented a positive consensus; IQR 3 or less inferred negative consensus; and IQR above 3 and less than 7 was considered a neutral opinion.

In round 2, the respondents met to review the results of round 1 and revise wording of the statements where appropriate. For statements that reached positive consensus in round 1, wording could still be revised following discussion. For statements that did not gain consensus, supporting data were reviewed, wording was amended as required and revised statements were scored. Further statements added as a result of discussion during the meeting were subsequently put to vote.

Disease-, Practice- and Patient-Focussed Unmet Needs in UC

Literature Search

During the debate surrounding unmet medical needs in UC, a number of additional unmet needs statements were discussed, which were not related to UC management. In order to develop an evidence-based consensus on these additional statements, a similar process was followed.

Three literature searches were conducted using PubMed, using the same format of "UC", combined with a number of secondary search terms from the discussions at the first panel meeting. The search was conducted for articles published between January 1, 2006 and April 1, 2017, and was restricted to English language articles and those involving human subjects. Different secondary search terms were used for each literature search (Table 2).

The combined results were subject to the following exclusion criteria: superseded by newer data; small or single-centre studies; paediatric UC; not specifically concerning UC; objective not aligned with search. The titles of the remaining articles were then screened for relevance. Abstracts of those articles considered potentially relevant were then assessed for eligibility, with the full text of those articles remaining subsequently assessed.

The results of the literature review were then used to refine the initial proposed unmet needs statements. The resulting statements formed the basis of a pre-meeting survey for the first round of a new Delphi process.

\section{Survey Participants}

The panel comprised 9 leading European gastroenterologists with expertise in IBD. All participants took part in the survey. 
Fig. 1. PRISMA diagram showing the flow

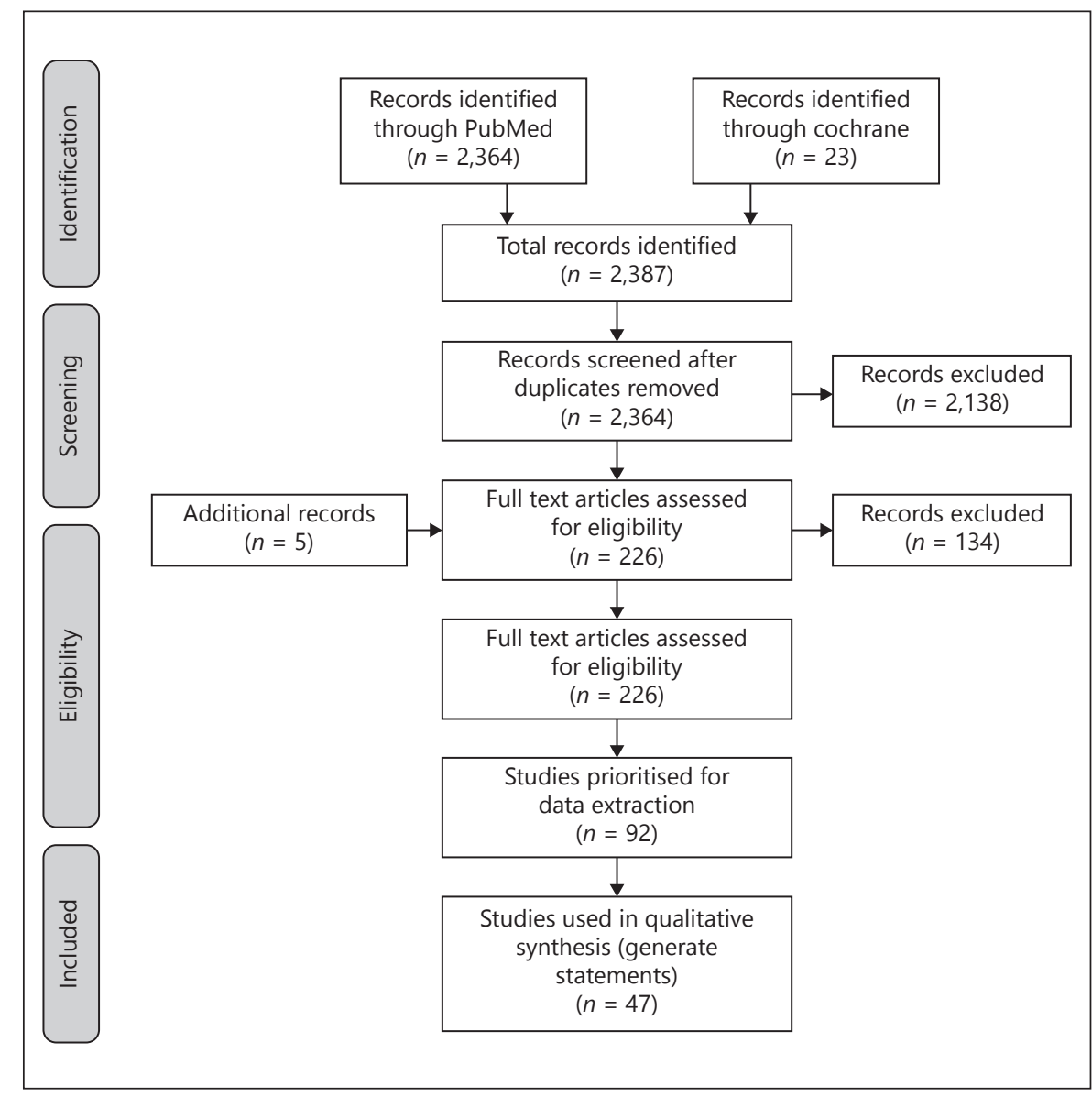
of steps in published data collection.

\section{Delphi Process}

As with the unmet medical needs consensus-building process, a modified Delphi process was utilised, consisting of 2 rounds: a survey followed by a live meeting.

The unmet needs statements developed as outputs of the literature search were sent to the 9 members of the Expert Panel as a survey, to ascertain their level of agreement with each statement.

The second round of the modified Delphi process saw the convening of the panel to review the unmet needs statements and the varying degrees of agreement reached through the survey. Individuals were afforded the opportunity to modify their survey responses in light of the group discussion, with discussions aiming to achieve consensus, again following the same process previously used. Once consensus on all statements had been reached, they were prioritised.

\section{Results}

\section{Unmet Medical Needs in UC}

Literature Search

After removal of duplicates, the titles or abstracts of 2,364 publications were reviewed for relevance. In all,
2,138 publications were deemed not relevant and excluded; of the remaining 226 publications, 92 were finally included for full review after application of exclusion criteria (PRISMA diagram; Fig. 1). These literature review findings were used to generate a total of 15 preliminary statements that were the basis of the questionnaire used in the first round of the Delphi process.

\section{Survey Results}

During the first round of scoring, consensus was reached on 11 of the 15 preliminary statements; no consensus was reached on the remaining 4 statements (Table 1). Following discussion, wording was revised for 8 of the 11 statements for which consensus was reached. Following discussion of the 4 statements for which no consensus was reached, one of the statements was divided into 2 separate statements, for both of which consensus was then reached; wording was revised on the remaining 3 statements, which then gained consensus.

During the meeting, an additional 14 areas of unmet need were proposed; of these, following discussions, the 
Table 3. Unmet medical needs in UC: expert panel statements (in 4 categories, a-d)

a. UC impacts patients' ability to lead a normal life

- A significant proportion of UC patients have reduced quality of life

- A proportion of UC patients have reduced ability to work

- Colectomies and hospitalisation rates are declining in the era of biologics, but further improvements can be made

- There is a gap between patient and caregiver perceptions in UC

b. Early diagnosis and treatment are important

- Reduction in time to diagnosis and timely, effective intervention have the potential to improve outcomes

- Extensive disease and/or severe disease activity at diagnosis are associated with poor prognosis

- Patients with proctitis require early and effective treatment to improve their quality of life over the long term

c. Existing therapeutic options have significant drawbacks

- Adherence to self-administered treatments in UC is poor

- Prolonged exposure (over 3 months) to, or repeated courses of, corticosteroids is/are associated with side effects that outweigh the clinical benefits

- Aminosalicylates may effectively treat UC, although they may be associated with lack of efficacy in some patients

- Thiopurines may effectively treat UC, although they may be associated with lack of efficacy and/or intolerance in some patients

- TNF inhibitors may require dose escalation and therapeutic drug monitoring to optimise treatment

- TNF inhibitors have improved remission rates in UC. One third of patients are primary non-responders and up to one half exhibit secondary loss of response

- Anti-integrins provide an alternative to TNF inhibitors, but comparative efficacy is unknown

d. There is a need for new therapeutic options

- Patients would benefit from additional treatment options to improve disease control and outcomes

- Alternative agents with a rapid onset of clinical effect would be of value in moderate-to-severe UC

- Patients usually prefer oral vs parenteral formulations of drugs with a comparable efficacy and safety profile

- European IBD societies should collaborate with stakeholders and lobby for continued investment in the education of HCPs and raise awareness of the treatment of UC through development, publication and dissemination of scientific research

HCPs, healthcare providers; IBD, inflammatory bowel disease; TNF, tumour necrosis factor; UC, ulcerative colitis.

group agreed to take forward 3 statements for further consensus development. Subsequently, consensus was reached for 2 of these 3 additional statements. Ultimately, 18 statements reached consensus (Table $3 \mathrm{a}-\mathrm{d}$ ). These statements could be categorised into 4 areas: impact of UC on patients' daily life; importance of early diagnosis and treatment; drawbacks of existing treatments; and need for new treatments.

\section{Unmet Needs Statements: In Four Categories}

UC Impacts Patients' Ability to Lead a Normal Life (Table $3 a$ ). Overall, UC patients can achieve levels of HRQoL comparable to norms for the general population [3]. However, ongoing presence of symptoms, use of corticosteroids, unemployment, female sex and smoking may be associated with reduced HRQoL in patients with UC [3]. UC in general is associated with a high prevalence of fatigue (44\%), severe depressive symptoms (14.9\%) and impairments in sexual function (20.6\%) [23]. Treatment regimens requiring multiple daily dosing can interfere with patients' daily life, negatively affecting adherence to therapy and leading to poorer long-term outcomes in UC [24]. Biologics have the potential to improve HRQoL [25].

With regard to the workplace, UC is associated with increases of up to $88 \%$ in absenteeism, $69 \%$ for sick leave, $66 \%$ for reduced capacity, 50\% for unemployment and $19 \%$ for disability pension - with the risk for receiving a disability pension highest in the 18-39-year age group $[26,27]$. Moreover, many patients undergoing colectomy persistently have work disability after the surgery, possibly due to long-term postoperative complications [27]. On the other hand, biologic agents have shown positive effects on improving absenteeism and presenteeism at work [26]. In a recent meta-analysis of randomised trials data, the TNF inhibitors infliximab and adalimumab were more effective than placebo in reducing the rate of UCrelated hospitalisation, whereas treatment with infliximab (but not adalimumab or golimumab) was associated with a reduced rate of colectomy at 54 weeks [28]. Some researchers have reported that biologics apparently had no impact on hospitalisation and colectomy rates $[29,30]$, 
whereas a recent focus paper by the Epidemiology Committee of European Crohn's and Colitis Organisation (ECCO) concluded that colectomy rates have dropped since the introduction of these drugs, but conceded that data on hospitalisations is heterogeneous and conflicting [31]. Future studies involving an extended follow-up period are required to answer this question definitively.

Patients and caregivers (physicians/nurses) differ in their perceptions of disease severity. In general, disease severity estimated by physicians was milder than was selfreported by patients; also, physicians estimated fewer flares and better overall quality of life than was self-reported by patients [32-34]. Both patients and caregivers do agree, however, that more regular interpersonal contact between them would have a positive impact on improving UC management [35].

Early Diagnosis and Treatment Are Important (Table 3b). Extensive UC involvement at diagnosis is associated with a severe disease course; extensive disease (Montreal E3; pancolitis) on the initial endoscopy was more frequent in patients with moderate-to-severe UC (rate of proximal disease location in mild, moderate and severe UC: 13, 21 and 30\%, respectively; $p=0.001$ ) [36]. Deep ulceration at colonoscopy is associated with poor prognosis [1]. Proctitis is a common feature of UC, with over $30 \%$ of patients presenting with disease limited to the rectum [37]. Proximal disease extension has been observed in over $28 \%$ of UC patients after a median of 10 years of follow-up [38]. Therefore, early and effective treatment of proctitis is needed. It is noteworthy that patients with proctitis have been excluded from most prospective randomised controlled trials $[9,10,12,39]$, and the effects of the majority of systemic treatments have not been specifically investigated in UC proctitis.

Rapidity of achieving remission as well as its sustainability are likely important factors in attaining treatment goals in UC [40]. In this regard, remission was achieved within 2 weeks following a single dose of infliximab in $27 \%$ of patients and a similar early response rate was observed for adalimumab [40]. The remission rate in UC patients treated with golimumab and vedolizumab was lower but comparable to that with infliximab and adalimumab: remission was achieved by $18 \%$ of patients receiving golimumab [9], whereas $17 \%$ of patients treated with vedolizumab entered clinical remission by week 6 [12].

Ultimately, remission may be defined as clinical improvement, mucosal healing, histologic healing and correction of the underlying immunological defect [40]. Although the progressive nature of UC is less certain than for Crohn's disease (CD), inadequately treated inflammation in UC is believed to enhance the risk of dysplasia and colon cancer. However, whether UC is associated with an increased long-term risk of death compared with the general population is debatable [41-43].

Existing Therapeutic Options Have Significant Drawbacks (Table 3c). A large number of clinical trials of 5-ASA in a variety of oral and topical formulations, mainly conducted in the 1980s-90s, have long-since established this drug as gold standard therapy for induction and maintenance of remission in mild-to-moderate UC [44]. However, long-term persistence with 5-ASA may be problematic, especially if corticosteroid courses are co-medicated (see below).

Corticosteroids have demonstrated good efficacy in inducing rapid clinical responses; however, these drugs are associated with significant unwanted side effects [45] and their use in UC patients may confer a hazard ratio for death of 2.81 (95\% CI 2.26-3.50) versus age-matched healthy controls over a 10-year period [42]. "Corticosteroid-free remission" is the common aim of clinical guidelines for the management of UC $[4,5]$. Immunomodulators in the setting of maintenance therapy refractory to 5-ASA or corticosteroid-dependent disease are associated with high rates of switching and augmentation with add-on therapies; in one large real-world population study in the United States, 30\% of patients experienced post-exposure complications during their index immunomodulator therapy and $73 \%$ relapsed while on treatment [46]. The 2016 ECCO guidelines recommend that only immunomodulators be used in refractory disease or in combination with TNF inhibitors, as the superior efficacy of infliximab in combination with azathioprine in steroid-refractory disease has been demonstrated [5].

In patients in whom corticosteroids are required to achieve remission, approximately $20 \%$ still require corticosteroid therapy at 1-year post-initiation [47]. Among 126 such "corticosteroid-dependent" patients who were switched to infliximab, half remained corticosteroid-free and without colectomy at 6 and 12 months. Significant predictors of maintaining corticosteroid-free remission in these individuals were co-medication with azathioprine and normalisation of C-reactive protein levels following switch to infliximab [47].

Primary failure of anti-TNF induction therapy occurs in $19-58 \%$ of patients in clinical trials [15]. In a metaanalysis of trials data on anti-TNF therapy using adalimumab, golimumab or infliximab the relative risk of achieving short- (6-8 weeks) and long-term (52-54 weeks) remission of UC favoured all 3 drugs at all doses tested 
versus placebo, with the $95 \%$ CIs mostly demonstrative of reaching a statistically significant difference [28]. However, the combined proportion of patients who achieved remission on these 3 TNF inhibitors was only $23 \%$ in the short term and $26 \%$ in the long term; by comparison, in patients receiving placebo the rates were 7.4 and $12.5 \%$, respectively, at the same time-points. Real-life remission rates with TNF inhibitors in UC are also low overall; lesser than one quarter patients achieve greater than 3-month clinical remission on these drugs [48].

In addition to primary failures, some patients who initially respond to TNF inhibitor therapy will eventually discontinue due to secondary loss of response (17-22\%) or toxicity $(<10 \%)$, and $19-40 \%$ of patients will require dose escalation to maintain efficacy [15]. Patients treated with TNF inhibitors have only a 1.76 -fold (95\% CI 1.462.14) higher likelihood of maintaining response for at least 52 weeks compared with those assigned to receive placebo [49]. Secondary loss of response to TNF inhibitors may be successfully overcome by increasing drug exposure (increasing dose or reducing dosing interval) or switching to another drug [50]. However, evidence suggests that treatment failure is even higher among patients undergoing second-line TNF inhibitor therapy; in a meta-analysis of studies in these individuals, the proportion who discontinued treatment due to loss of response was $68-77 \%$ by the end of year 1 and $82-90 \%$ by the end of year 2 [15].

For patients who experience primary or secondary treatment failure with anti-TNF agents, switching to a biologic with a different mechanism of action may be appropriate. Vedolizumab is a monoclonal antibody targeting $\alpha_{4} \beta_{7}$ integrin leading to gut-selective inhibition of immune cell recruitment and thereby exerts anti-inflammatory activity in UC [15]. Vedolizumab has been demonstrated statistically and significantly to be more effective than placebo in terms of clinical response rate, maintenance of remission and mucosal healing [12, 51]. Moreover, long-term clinical study data in over 2,800 IBD patients who were treated for up to 5 years demonstrate that this drug has a favourable safety profile with no increased risk of serious or opportunistic infections or malignancy versus placebo [52]. Head-to-head comparative studies of vedolizumab versus TNF inhibitors are needed [53].

Adherence to UC treatments, including 5-ASA, is often poor and non-adherence is associated with enhanced risk of relapse [54]. 5-ASA and azathioprine seem to have particularly poor rates of adherence, with patients on these drugs missing 45 and 25\%, respectively, of their total prescribed doses - mostly involuntarily due to forget- fulness [55]. Recently, once-daily dosing for 5-ASA has gained popularity and this strategy has been demonstrated to improve adherence over thrice-daily dosing, with non-inferior efficacy, in one UC series [56]. A systematic review evaluating adherence to anti-TNF therapy in IBD reported a pooled rate of $82.6 \%$ (83.1\% in adalimumab and $70.7 \%$ in infliximab-treated patients) [57].

There Is a Need for New Therapeutic Options (Table 3d). In clinical practice, there remains a high rate of incomplete or non-response to UC medications, indicating a need for new therapeutic strategies [58]. Moreover, in a survey of 256 moderate-to-severe UC patients from 11 European countries, $48 \%$ were dissatisfied with their current treatment [34]. Effectiveness, long-lasting action, rapid onset of action and few side effects were considered important or very important by this cohort of patients [34].

Up to one third of patients receiving 5-ASA are not satisfied with this therapy [33]. However, only a small proportion of UC patients may complain of treatment dissatisfaction with their doctor [32]. Patients' decisions when selecting a TNF inhibitor are influenced by ease of medication use, time required to take treatments, time interval between drug dosing, scientific evidence for efficacy and fear of syringes [59]. A cross-sectional study of patients enrolled at the IBD unit of a French hospital revealed that those receiving infliximab spent $6.5 \mathrm{~h}$ away from home or work for each infliximab infusion [60]. For oral therapy, UC patients prefer medications that present no swallowing difficulties, are taken once daily and have fewer tablets per dose regimen [55].

New drug classes such as JAK inhibitors, which reduce the expression of a number of inflammatory cytokines implicated in UC, including tofacitinib, filgotinib and upadacitinib (all in phase III clinical trials), and T cellinhibitory S1P receptor modulators, such as ozanimod (also in phase III) offer potential therapeutic benefits in UC [61].

Disease-, Practice- and Patient-Focussed Unmet Needs in $U C$

Literature Search

Following the completion of the first unmet needs in UC consensus-finding exercise, evidence relating to the additional unmet needs suggested during the first panel meeting was sought through additional literature searches. A combined total of 2,817 articles were identified. These were cross-checked for duplicates and the exclusion criteria applied, before being screened for relevance and assessed for eligibility (Fig. 2). A total 46 articles were deemed appropriate for inclusion, and these were utilised 


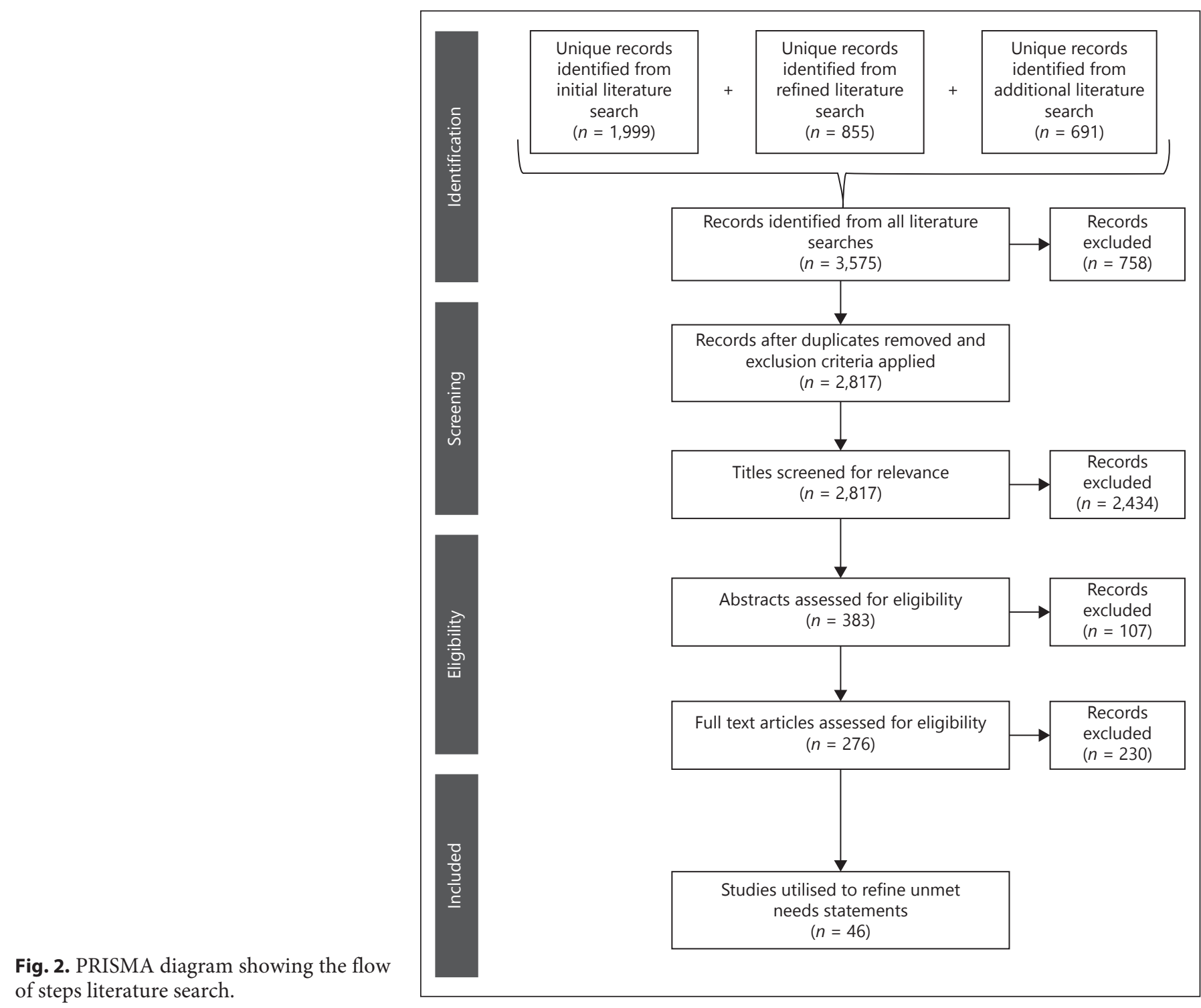

to assess the 11 preliminary unmet needs statements. This assessment resulted in an expanded set of 14 unmet needs statements across 3 categories: disease-focused unmet needs; therapy-focused unmet needs, and patient-focused unmet needs. These statements were included in the survey for distribution to the experts that formed round 1 of the modified Delphi process.

\section{Delphi Process}

The round 1 survey of unmet needs statements saw consensus being reached for 10 of the 14 statements (Table 4). All statements were individually and comprehensively discussed during the Expert Panel meeting that formed round 2 of the process. Those statements that had not reached consensus during the round 1 survey were further refined and voted upon again. This process produced a prioritised set of 12 unmet needs statements across a refined set of categories: disease-focused; practice-focussed, and patient-focused. Consensus was not reached during the meeting for 1 statement. Subsequent to the meeting, this statement was refined and put to an online vote, achieving consensus at that time. All unmet needs statements can be seen in Table 5 .

\section{Unmet Needs Statements}

Disease-Focused Unmet Needs Statement

1. There are gaps in the current understanding of the natural history of UC. Heterogeneity pervades all aspects 
Table 4. Preliminary unmet needs statements and results of round 1 survey

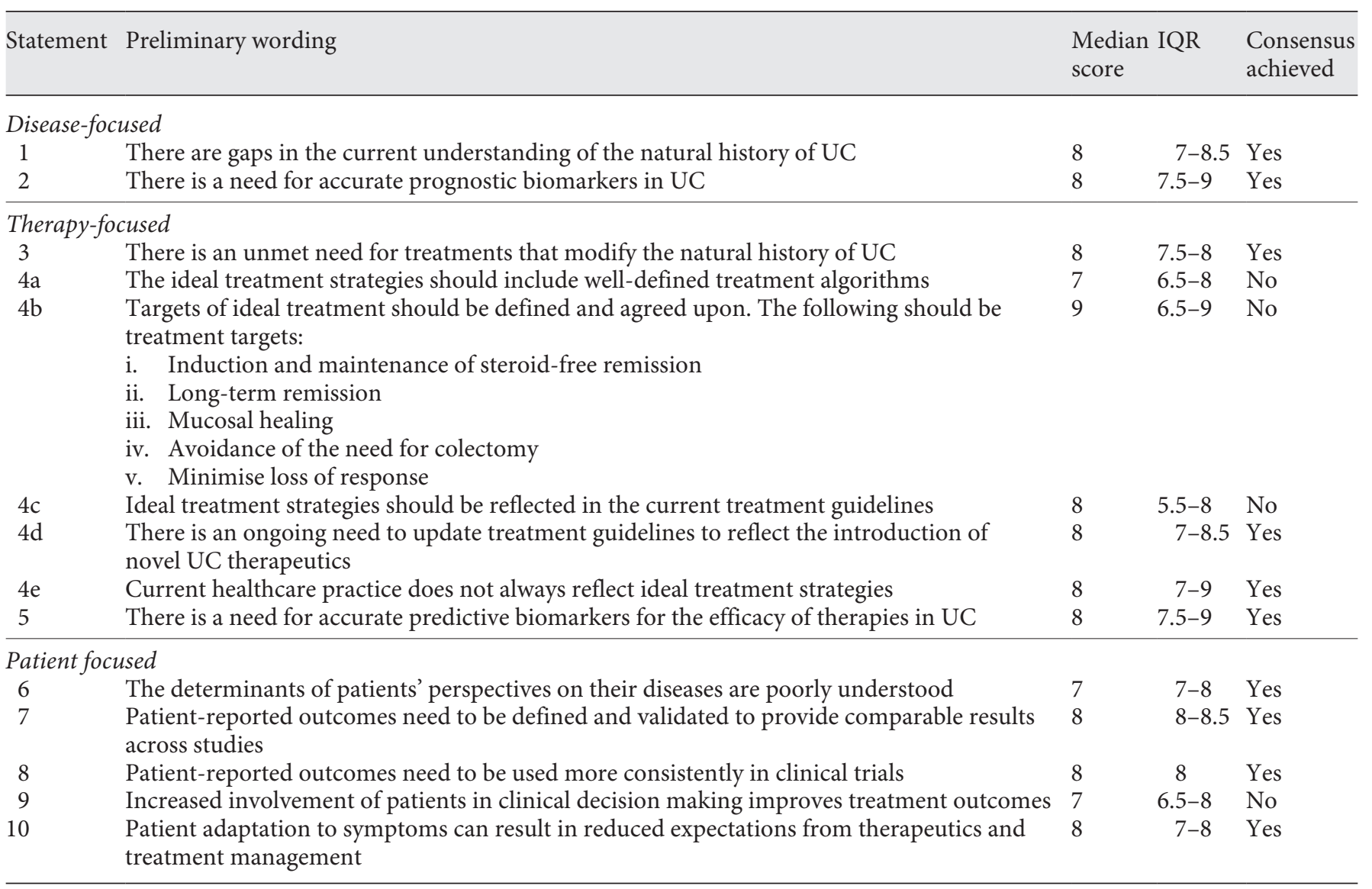

IQR, interquartile range; UC, ulcerative colitis.

of UC, from incidence rates around the world to disease course in individual patients.

Geographically, incidence rates of UC vary considerably in different parts of the world, and these rates according to time period and location studied, with different rates in Asia [20] and Europe, for example [16, 17].

Clinically, variation between individuals is seen from the time of diagnosis [62], with some patients presenting with intermittent flares while other exhibit chronic symptoms. The disease course of UC may differ between patients [62]. Symptoms associated with UC can obviously impair patient quality of life, while the underlying inflammation may lead to the progression of disease extent, colectomy and/or the development of colitis-associated colorectal cancer, with varying levels of risk associated to some of these outcomes in different geographies [62]. The pathophysiology of disease, as well as genetic or environ- mental factors underlying these disparate observations, is not yet fully understood.

Approaches to the treatment of UC are changing, with a growing emphasis on the use of immunosuppressant and biologic therapies. However, the impact of these drugs on the natural history of UC is poorly understood at present $[62,63]$. In addition, further knowledge of the pathophysiology of UC will be critical to the future development of novel therapeutic targets [64].

\section{Practice-Focused Unmet Needs Statements}

2. For a substantial proportion of patients there is an unmet need for treatments that improve the natural history of UC. During the early stages of UC, relapses are associated with a hastening of disease progression [65]. Patients who regularly use oral aminosalicylates are 5.8 times more likely to experience disease regression than 
Table 5. Unmet needs in ulcerative colitis: 2 nd expert panel statements in 3 categories

Disease-focused unmet needs

1 There are gaps in the current understanding of the natural history of UC

Practice-focused unmet needs

2 For a substantial proportion of patients there is an unmet need for treatments that improve the natural history of UC

3a There is a current unmet medical need to define and achieve optimal treatment goals. These include:

i. Improvement of quality of life

ii. Minimisation of adverse events

iii. Reduction of extent of tissue damage

iv. Reduction of hospitalisation

v. Reduction of colectomy rates

vi. Reduction of incidence of cancer

$3 \mathrm{~b}$ To achieve these goals, treatment targets should be defined and include:

- Induction and maintenance of long-term steroid-free remission

- Resolution of mucosal inflammation

4 There is a need to bridge the existing gap between current healthcare practice and optimal treatment strategies

5 There is a need for accurate biomarkers to assist selection of the most appropriate therapies in UC

6 There is an ongoing need to update treatment strategies including the introduction of novel UC therapies

7 Optimal treatment strategies should take into account recommendations and guidelines

Patient-focused unmet needs

8 PROs beyond stool frequency and rectal bleeding need to be defined and validated to provide comparable results across studies

9 Patients' perspectives and expectations are poorly understood

10 Active involvement of patients in clinical decision making improves patient satisfaction and probably disease outcomes

11 Patients may reset their tolerance threshold to the symptoms and this can result in lower treatment expectations

PROs, patient-reported outcomes; UC, ulcerative colitis.

those who do not [65], and oral aminosalicylates may also protect against the proximal extension of mucosal inflammation in UC [65]. This suggests a disease-modification role for oral aminosalicylates in UC [65]. There is also evidence that thiopurines and anti-TNF treatments have the potential for disease modification in UC $[63,66]$. The term "disease-modifying anti-rheumatic drugs" is widely used in the field of rheumatoid arthritis, and it is possible that a similar concept could be adopted in IBD [66]. Possible terms for the use of disease modifying agents such as oral aminosalicylates or anti-TNFs in UC might be "disease-modifying anti-inflammatory bowel disease drugs" or "intestinal damage-preventing anti-UC drugs" [63]. The latter would imply that these drugs control inflammation and thereby minimise complications such as dysplasia and cancer. The aim of treating UC using disease-modifying drugs, beyond the goals of improving symptoms and inducing remission, would be to prevent extended and permanent effects of disease activity, such as bowel damage and the need for colectomy [66].

3a. There is a current unmet medical need to define and achieve optimal treatment goals in UC. These include:

i. Improvement of quality of life

ii. Minimisation of adverse events

iii. Reduction of tissue damage

iv. Reduction of hospitalisation

v. Reduction of colectomy rates

vi. Reduction of incidence of cancer

3b. To achieve these goals, treatment targets should be defined and include:

i. Induction and maintenance of long-term steroidfree remission

ii. Resolution of mucosal inflammation

According to the 2016 ECCO UC management guideline, the goal of maintenance therapy is steroid-free remission, defined both clinically and endoscopically [1]. The purpose of maintaining clinically defined steroid- 
free remission is to improve patient quality of life and avoid the complications of prolonged steroid use. Endoscopic remission is predictive of good outcomes; in addition to improving symptoms, maintaining endoscopic remission is associated with reduced colorectal cancer incidence, with macroscopically normal looking colonoscopy considered to be associated with reduced cancer risk [67].

Histologic remission is distinct from endoscopic mucosal healing and histology may have a higher sensitivity than endoscopy for epithelial damage and risk of relapse [1]. It is associated with freedom from symptoms, lowered risk of relapse and reduced hazard for surgery, hospitalisation and colorectal cancer in patients with UC [68]. Currently, however, no standard definition of histological remission exists and it is not currently recommended as a goal in daily clinical practice [1].

4. There is a need to bridge the existing gap between current healthcare practice and optimal treatment strategies in UC. The treatment decisions made by IBD care providers in daily practice are often different from those recommended by experts or supported by latest research outcomes. In addition, gastroenterologists may experience difficulty in assessing disease activity or severity as recommended by guidelines, and in applying treatment recommendations, in daily practice [69]. A survey conducted with community gastroenterologists and UC experts in the United States identified that, when it came to areas of uncertainty in UC treatment, dramatic variations in approach existed between the 2 groups [70].

Where a gulf exists between recommendations and clinical practice, this may be owing to limitations within healthcare systems, financial constraints or poor patient adherence to treatment regimens.

5. There is a need for accurate biomarkers to assist selection of the most appropriate therapies in UC. Biomarkers in UC are necessary for accurately predicting the efficacy of specific therapy choices and assessing prognosis. While there have been advances in the molecular fingerprinting of UC, very few validated biomarkers exist, either in the gut mucosa or body fluids [71], and so the need remains for reliable, cost-effective biomarkers to facilitate clinical management [72].

Research is ongoing in relation to biomarkers, with a number of promising developments. The presence of neutrophils in the epithelium is a marker of histological activity and is associated with higher faecal calprotectin levels [73]. Gene microarray experiments have revealed a signature CD8 T-cell transcriptional profile that may be predictive of the need for future treatment escalation, which may allow for the potential of a worsening disease evolution to be recognised at diagnosis of UC [19]. Preliminary findings suggest that expression of the peripheral blood T-cell surface marker CD25 and levels of interleukin-5 secretion in vitro may predict response to antiTNF drugs [74].

Clinical data demonstrating and validating correlations between inflammatory mediators and their metabolites with levels of disease severity in UC could form a useful basis for the development of routine tests to inform the likely effectiveness of treatments [71, 74].

More generally, biomarkers that predict a lack of response may prove to be more useful in clinical practice than those predictive of a positive response. Biomarkers that differentiate drug classes by efficacy in individual patients would also be of great value to practising physicians.

6. There is an ongoing need to update treatment strategies including the introduction of novel UC therapies. Treatment guidelines recommend the best available practice at the time of their development. These guidelines must, therefore, be continually reviewed and revised in light of emerging new treatments and approaches. The ECCO e-Guide reflects this need [75], being a web-based collection of treatment algorithms that is continually updated based upon the latest ECCO guidelines [76].

7. Optimal treatment strategies for UC should take into account recommendations and guidelines. Treatment recommendations offer a number of benefits, providing management guidelines based upon best-available evidence, and providing a useful additional source of disease education for physicians. There are influential guidelines for the treatment of UC, including ECCO guidelines [76] and the Toronto consensus [77], which contain treatment recommendations based upon a variety of factors, including disease severity, distribution and prior treatment.

It should be recognised, however, that the utilisation of guidelines and treatment algorithms in clinical practice may not be possible, as they may not be directly applicable to individual patients with complex presentations.

Patient-Focused Unmet Needs Statements

8. PROs beyond stool frequency and rectal bleeding need to be defined and validated to provide comparable results across studies. PROs are important tools for determining disease severity and the success of a treatment, enabling assessment of the patient's perspective on the impact of their disease in addition to measurements of physical symptoms [78]. Assessing satisfaction in patients through PROs may positively influence quality of care in IBD [79]. 
PROs should be standardised, validated questionnaires that evaluate a patient's perception of their health condition without clinical interpretation of that response [80]. They also have an increasingly important role in the evaluation and approval of new treatments for IBDs [81]. Currently, however, no UC PROs have been validated by regulatory authorities for this purpose [81].

In one clinical investigation, a 2-item, Mayo Clinic Score-derived PRO consisting of rectal bleeding and stool frequency scores yielded statistically significant differences between active treatment and placebo groups when combined with an endoscopy subscore [81]. A coprimary endpoint such as this may provide a suitable outcome measure for UC clinical trial use, while the lengthy process of developing a validated $\mathrm{PRO}$ is underway [81].

9. Patients' perspectives and expectations are poorly understood. The impact of IBD is not only felt by patients during flares of their disease, but between flares too, with some estimates suggesting rates of anxiety as high as 35\% during periods of remission [82]. Over time, in addition to the physical symptoms of disease (such as fatigue, a common and bothersome symptom that may affect patients' mood) [83], the psychological impact can have an increasingly important effect on patients' well-being. A survey of UC patients in the United States evaluating the psychological impact of the disease revealed that in excess of $80 \%$ of respondents worried about the long-term effects of UC, and that having UC made life more stressful [33]. Furthermore, $62-70 \%$ of respondents reported feelings of embarrassment or depression related to their disease [84].

The impact of UC on patient well-being may be greater than that of other chronic diseases [85]. In total, 53\% of respondents to the same patient survey reported that they felt their UC was taking over their life; a markedly higher percentage than is seen with chronic conditions such as asthma (19\%), migraine (37\%) or rheumatoid arthritis (44\%) [84].

It is, therefore, important that physicians develop close and effective relations with their patients, that they remain aware of their patients' psychological well-being, and that medical care be integrated with psychological and social support [86-88].

10. Active involvement of patients in clinical decision making improves patient satisfaction and probably disease outcomes. The treatment and control of UC is met with varying degrees of success, and therapeutic decision making is usually symptomatology-led. It is increasingly the case, however, that patients are becoming more in- volved in the management of their disease [89]. In fact, $98 \%$ of patients in a study exploring patient empowerment considered active involvement in decision making to be quite or very important [90]. Patient empowerment has also been shown to improve adherence, as demonstrated by a group of UC patients receiving 5-ASA therapy who had access to a web-based education and selftreatment package [91]. These same patients demonstrated improved quality of life and reduced relapse duration compared to a control group receiving usual care [91].

Whether such improvements in patient outcomes are directly related to patient involvement in treatment decision-making or are an artefact of, for example, better adherence in empowered patients is unknown. However, increased involvement seems likely to positively influence a patient's satisfaction in their treatment. An expert consensus process initiated by the International Organization for the Study of Inflammatory Bowel Disease supported the use of PROs in defining remission, and acknowledged the need to address a patient's individual treatment goals [92].

11. Patients may reset their tolerance threshold to the symptoms and this can result in lower treatment expectations. A study of IBD patients in Japan demonstrated that while increasing medication was the most effective way to improve symptoms during a disease flare, making dietary changes and sleeping more were the most commonly used coping strategies [93]. This suggests that some patients resort to lifestyle modifications as a way of coping with their symptoms, instead of or in addition to receiving additional medical treatments.

Even when disease activity remains unchanged, patient perceptions of their disease can be improved through the use of psychotherapy. This has been demonstrated in a randomised control study examining stress management in a cohort of patients with IBD showing continuous disease activity or recent relapse, where professional stress management psychotherapy significantly improved disease-specific quality of life, in spite of unaltered disease activity [94].

\section{Discussion}

A thorough review of the literature formed the basis of an initial 15 statements, which were subsequently expanded to 18 statements, relating to medical unmet needs in UC, and a modified Delphi process was used to establish consensus among a panel of European-based gastro- 
enterologists with expertise in IBD. A 2nd Expert Panel meeting identified a number of additional unmet needs. These additional unmet needs form the basis of an updated systematic literature review. The modified Delphi process resulted in 12 unmet needs consensus statements, categorised as disease-, practice- or patient-focused.

Of the 18 initial medical unmet needs statements, 4 relate to UC patients' inability to lead a normal life. The present research brings a clear message that better understanding is needed of patients' views regarding the impact of UC and its treatment on their lives [32,33]. A further 3 of the 18 consensus statements relate to the importance of early diagnosis and treatment of UC. The onset of UC may be insidious and in many individuals, symptoms may be present for weeks or longer before clinician advice is sought [1]. A good level of awareness of UC is needed in primary care settings to ensure that patients are referred to specialist care as soon as possible so as to minimise delays in diagnosis. Although there is no evidence that duration of UC at the start of TNF inhibitor therapy has any impact on long-term disease control, there may be a case for early aggressive management using this class of drugs [53]. It is known that early intervention is beneficial in CD [95]; however, further research is required to ascertain whether this is also the case in UC. Furthermore, optimal outcome measures in studies that investigate disease activity over the longer term are unknown; corticosteroid dependency, hospitalisations, disability and surgery are candidate proxies.

Seven of the 18 unmet needs statements address drawbacks of existing UC treatments. 5-ASA is well established as the mainstay of treatment for mild-to-moderate cases; however, long-term adherence to this drug seems difficult to maintain. While corticosteroids may be highly effective induction agents, they are inappropriate as maintenance therapies [5]. Thiopurines, on the other hand, are not efficacious as induction agents [95]. They are effective in combination with anti-TNF therapy in some patients. However, in a clinical trial comparing infliximab monotherapy, azathioprine monotherapy, and combination therapy with both these agents, less than $40 \%$ of patients in the combination therapy group achieved corticosteroid-free remission at 16 weeks, and in monotherapy groups this endpoint was achieved in less than one quarter patients [11].

The next 3 unmet needs statements highlight the need for new therapeutic options in UC. In the management of this disease, long-term control is paramount and possibly more important than rapid improvement of symptoms, although patients with severe UC favour fast-acting ther- apy. While some patients may prefer oral over parenteral therapies, efficacy is their main concern [34]. There is an unmet need for small molecule drugs that confer comparable efficacy to injections/infusions [61]. The final statement calls for more investigator collaboration and lobbying to promote continued investment in the education of healthcare practitioners and raise awareness of the treatment of UC through the development, publication and dissemination of scientific research.

The additional 12 disease-focused unmet needs statement agreed serve to highlight gaps in clinicians' knowledge of the natural history of UC, including unsolved questions around the aetiology of the disease, and heterogeneous patterns of progression, as well as idiosyncrasies in response to treatments. It is apparent that significant knowledge is required on how current and new therapies may impact or alter the disease course of UC.

The practice-focused unmet needs statements consider the need for new therapies that are able to change the disease course of UC, as well as emphasising the degree to which clinical practice diverges from recommendations and guidelines. While it is apparent that guidelines are always evolving, the need for treatment strategies to reflect guidelines is identified. These statements also emphasise the need for effective, practical biomarkers; research into a number of candidates is ongoing.

Considering unmet needs from the patient perspective raises the need for validated PROs to be developed for use in future clinical trials, given that no regulator-approved, validated PROs currently exist. There is also a clear desire for patients to be more involved in the management of their disease, which is supported by positive data suggesting that this can lead to improvements in both adherence and disease outcomes. Finally, consensus was gained that patients' expectations vary over time as they adapt to living with UC, which may affect their subjective responses to treatment.

It should be acknowledged that the unmet needs statements presented in this study are the opinion of a small group of gastroenterologists, which can be considered a limitation of this study. The consensus reached following in-depth discussions was, however, supported by an extensive literature review.

In conclusion, extensive literature reviews and Delphi exercises identified a considerable number of outstanding problems in the current management of UC. These findings can help provide direction for future research and act as an impetus for further improving disease management and further engaging UC patients in setting goals and other treatment-related decisions. 


\section{Acknowledgements}

Medical writing assistance was provided by Synergy Medical and this service was funded by Pfizer.

\section{Authors' Declarations of Personal Interests}

S.D.: serves as speaker, consultant, and/or advisory board member for Abbvie, Ferring, Hospira, Johnson and Johnson, Merck, MSD, Takeda, Mundipharma, Pfizer Inc, Tigenix, UCB Pharma, Vifor, Biogen, Celgene, Allergan, Celltrion, Sandoz, Boehringer Ingelheim, Gilead, Alfa Wassermann. M.A.: has received honoraria from Abbvie, Celgene, Ferring, Genentech, Janssen, Mayoli, MSD, Novartis, Pfizer, Takeda, Tillots. A.A.vB.: has served as speaker, consultant or advisory member for or has received research funding from AbbVie, Dutch Ministry of Health, Ferring, Janssen, MSD, Pfizer, Takeda, Tramedico, and ZonMW. I.D.: has served on advisory boards and as a consultant with Takeda, Abbvie, Pfizer, Janssen, Ferring, Genentech, Rafa laboratories, Roche, MSD, Given Imaging and has served as a speaker and is teaching with Falk Pharma, Ferring, Takeda, Abbvie, Pfizer, Janssen, Genentech. J.P.G.: has served as speaker, consultant, and advisory member for or has received research funding from MSD, AbbVie, Hospira, Pfizer, Kern Pharma, Biogen, Takeda, Janssen, Roche, Ferring, Faes Farma, Shire Pharmaceuticals, Dr. Falk Pharma, Tillotts Pharma, Chiesi, Casen Fleet, Gebro Pharma, Otsuka Pharmaceutical, Vifor Pharma. A.H.: has served as consultant, advisory board member or speaker for AbbVie, Atlantic, Bristol-Myers Squibb, Celltrion, Falk, Ferring, Janssen, MSD, Napp Pharmaceuticals, Pfizer, Pharmacosmos, Shire and Takeda. She also serves on the Global Steering Committee for Genentech. P.L.L.: has been a speaker and/or advisory board member for: AbbVie, EGIS, Falk Pharma GmbH, Ferring, Genetech, Jansen, Kyowa Hakko Kirin Pharma, Mitsubishi Tanabe Pharma Corporation, MSD, Otsuka Pharma, Pharmacosmos, Pfizer, Roche, Shire, and Takeda. P.L.L.: has also received unrestricted research grants from: AbbVie, MSD, and Pfizer. F.M.: has served as speaker and received honoraria from Merck Sharp and Dohme, AbbVie, Vifor Pharma, Dr. Falk Pharma, Laboratórios Vitória, Ferring, Hospira, and Biogen. L.P.B.: has received honoraria from Merck, AbbVie, Janssen, Genentech, Mitsubishi, Ferring, Norgine, Tillotts, Vifor, Hospira/Pfizer, Celltrion, Takeda, Biogaran, Boehringer-Ingelheim, Lilly, HACPharma, Index Pharmaceuticals, Amgen, Sandoz, Forward Pharma GmbH, Celgene, Biogen, Lycera, Samsung Bioepis. S.S.: has served as speaker/invited faculty and/or participated in advisory meetings for: Abbvie, Allergosan, Celgene, Celltrion, Falk, Ferring, Gilead, Johnson\&Johnson, Novartis, MSD, Pfizer, Roche/Genentech, Shield, Shire, Samsung, Takeda, Tillotts. D.T.: has served as speaker, consultant and advisory board member for the following organisations: Abbvie, Ferring, Pfizer, MSD, Takeda, Falk, Sandoz. S.V.: serves as speaker, consultant and/or advisory board member for the following organisations: Abbvie, Ferring, Pfizer, MSD, Takeda, UCB, Vifor, Celgene, Janssen, Falk, and Tillotts. J.H.: has served as speaker and/or advisory board member: AbbVie, Celgene, Ferring, Hospira, Janssen, Medivir, MSD, Pfizer, Prometheus, Sandoz/Novartis, Shire, Takeda, Tillotts Pharma, Vifor Pharma and grant support from Janssen, MSD, and Takeda. S.V.: has received grant support from AbbVie, MSD, Pfizer and Takeda; received speaker fees from AbbVie, MSD, Takeda, Ferring, Dr. Falk Pharma, Hospira, Pfizer and Tillotts; and served as a consultant for AbbVie, MSD, Takeda, Ferring, Genentech/Roche, Shire, Pfizer, Galapagos, Mundipharma, Hopira, Celgene, Second Genome and Janssen.

\section{Disclosure Statement}

The authors declare that they have no conflicts of interest to disclose.

\section{Funding Source}

This manuscript was developed with an unrestricted grant from Pfizer Inc. Medical writing support was provided by Synergy Medical.

\section{Author Contributions}

All authors interpreted the results, edited and finally approved the manuscript prior to submission.

\section{Guarantor of Article}

Séverine Vermeire and Jonas Halfvarson.

\section{References}

1 Magro F, Gionchetti P, Eliakim R, et al: Third European evidence-based consensus on diagnosis and management of ulcerative colitis. Part 1: definitions, diagnosis, extra-intestinal manifestations, pregnancy, cancer surveillance, surgery, and ileo-anal pouch disorders. J Crohns Colitis 2017;11:649-670.

2 Collins P, Rhodes J: Ulcerative colitis: diagnosis and management. BMJ 2006;333:340-343.

3 Hoivik ML, Moum B, Solberg IC, Cvancarova $\mathrm{M}$, Hoie O, Vatn MH, Bernklev T; IBSEN
Study Group: Health-related quality of life in patients with ulcerative colitis after a 10-year disease course: results from the IBSEN Study. Inflamm Bowel Dis 2012;18:15401549.

4 Bressler B, Marshall JK, Bernstein CN, Bitton A, Jones J, Leontiadis GI, Panaccione R, Steinhart AH, Tse F, Feagan B; Toronto Ulcerative Colitis Consensus Group: Clinical practice guidelines for the medical management of nonhospitalized ulcerative colitis: the Toron- to consensus. Gastroenterology 2015; 148: 1035-1058.

5 Harbord M, Eliakim R, Bettenworth D, Karmiris K, Katsanos K, Kopylov U, Kucharzik T, Molnár T, Raine T, Sebastian S, de Sousa HT, Dignass A, Carbonnel F; European Crohn's and Colitis Organisation [ECCO]: Third European evidence-based consensus on diagnosis and management of ulcerative colitis. Part 2: current management. J Crohns Colitis 2017;11:769-784. 
6 Danese S, Colombel JF, Peyrin-Biroulet L, Rutgeerts P, Reinisch W: Review article: the role of anti-TNF in the management of ulcerative colitis - past, present and future. Aliment Pharmacol Ther 2013;37:855-866.

7 Rutgeerts P, Sandborn WJ, Feagan BG, Reinisch W, Olson A, Johanns J, Travers S, Rachmilewitz D, Hanauer SB, Lichtenstein GR, de Villiers WJ, Present D, Sands BE, Colombel JF: Infliximab for induction and maintenance therapy for ulcerative colitis. N Engl J Med 2005;353:2462-2476.

8 Sandborn WJ, van Assche G, Reinisch W, Colombel JF, D'Haens G, Wolf DC, Kron M, Tighe MB, Lazar A, Thakkar RB: Adalimumab induces and maintains clinical remission in patients with moderate-to-severe ulcerative colitis. Gastroenterology 2012;142:257-265.

9 Sandborn WJ, Feagan BG, Marano C, Zhang $\mathrm{H}$, Strauss R, Johanns J, Adedokun OJ, Guzzo C, Colombel JF, Reinisch W, Gibson PR, Collins J, Järnerot G, Hibi T, Rutgeerts P; PURSUIT-SC Study Group: Subcutaneous golimumab induces clinical response and remission in patients with moderate-to-severe ulcerative colitis. Gastroenterology 2014;146:8595.

10 Sandborn WJ, Feagan BG, Marano C, Zhang $\mathrm{H}$, Strauss R, Johanns J, Adedokun OJ, Guzzo C, Colombel JF, Reinisch W, Gibson PR, Collins J, Järnerot G, Rutgeerts P; PURSUITMaintenance Study Group: Subcutaneous golimumab maintains clinical response in patients with moderate-to-severe ulcerative colitis. Gastroenterology 2014;146:96-109.

11 Panaccione R, Ghosh S, Middleton S, Márquez JR, Scott BB, Flint L, van Hoogstraten HJ, Chen AC, Zheng H, Danese S, Rutgeerts P: Combination therapy with infliximab and azathioprine is superior to monotherapy with either agent in ulcerative colitis. Gastroenterology 2014;146:392-400.

12 Feagan BG, Rutgeerts P, Sands BE, Hanauer S, Colombel JF, Sandborn WJ, Van Assche G, Axler J, Kim HJ, Danese S, Fox I, Milch C, Sankoh S, Wyant T, Xu J, Parikh A; GEMINI 1 Study Group: Vedolizumab as induction and maintenance therapy for ulcerative colitis. N Engl J Med 2013;369:699-710.

13 Tulchinsky H, Dotan I, Halpern Z, Klausner JM, Rabau M: A longitudinal study of quality of life and functional outcome of patients with ulcerative colitis after proctocolectomy with ileal pouch-anal anastomosis. Dis Colon Rectum 2010;53:866-873.

14 Hashavia E, Dotan I, Rabau M, Klausner JM, Halpern Z, Tulchinsky H: Risk factors for chronic pouchitis after ileal pouch-anal anastomosis: a prospective cohort study. Colorectal Dis 2012;14:1365-1371.

15 Gordon JP, McEwan PC, Maguire A, Sugrue DM, Puelles J: Characterizing unmet medical need and the potential role of new biologic treatment options in patients with ulcerative colitis and Crohn's disease: a systematic review and clinician surveys. Eur J Gastroenterol Hepatol 2015;27:804-812.
16 Ng SC, Shi HY, Hamidi N, Underwood FE, Tang W, Benchimol EI, Panaccione R, Ghosh S, Wu JCY, Chan FKL, Sung JJY, Kaplan GG: Worldwide incidence and prevalence of inflammatory bowel disease in the 21st century: a systematic review of population-based studies. Lancet 2018;390:2769-2778.

17 Kaplan GG: The global burden of IBD: from 2015 to 2025. Nat Rev Gastroenterol Hepatol 2015;12:720-727.

18 Feuerstein JD, Cheifetz AS: Ulcerative colitis: epidemiology, diagnosis, and management. Mayo Clin Proc 2014;89:1553-1563.

19 Lee JC, Lyons PA, McKinney EF, Sowerby JM, Carr EJ, Bredin F, Rickman HM, Ratlamwala H, Hatton A, Rayner TF, Parkes M, Smith KG: Gene expression profiling of CD8+ T cells predicts prognosis in patients with Crohn disease and ulcerative colitis. J Clin Invest 2011; 121:4170-4179.

20 Bossuyt P, Baert F, Coenegrachts JL, De Vos M, Dewit O, Ferrante M, Fontaine F, Mana F, Vandervoort J, Moreels T: Belgian IBD research and development group: evaluation of step up therapy in patients with early ulcerative colitis: a prospective cohort study. Poster P347 presented at ECCO 2017.

21 Linstone HA, Murray T (eds): The Delphi Method. Techniques and Applications. Boston, Addison-Wesley, 1975.

22 Rowe G, Wright G: The Delphi technique: past, present, and future prospects - introduction to the special issue. Technol Forecast Soc Chang 2011;78:1487-1490.

23 Bokemeyer B, Hardt J, Hüppe D, Prenzler A, Conrad S, Düffelmeyer M, Hartmann P, Hoffstadt M, Klugmann T, Schmidt C, Weismüller J, Mittendorf T, Raspe H: Clinical status, psychosocial impairments, medical treatment and health care costs for patients with inflammatory bowel disease (IBD) in Germany: an online IBD registry. J Crohns Colitis 2013;7:355-368.

24 Kane SV: Systematic review: adherence issues in the treatment of ulcerative colitis. Aliment Pharmacol Ther 2006;23:577-585.

25 LeBlanc K, Mosli MH, Parker CE, MacDonald JK: The impact of biological interventions for ulcerative colitis on health-related quality of life. Cochrane Database Syst Rev 2015; 9:CD008655.

26 Büsch K, da Silva SA, Holton M, Rabacow FM, Khalili H, Ludvigsson JF: Sick leave and disability pension in inflammatory bowel disease: a systematic review. J Crohns Colitis 2014;8:1362-1377.

27 Høivik ML, Moum B, Solberg IC, Henriksen $M$, Cvancarova M, Bernklev T; IBSEN Group: Work disability in inflammatory bowel disease patients 10 years after disease onset: results from the IBSEN Study. Gut 2013;62:368-375.

28 Lopez A, Ford AC, Colombel JF, Reinisch W, Sandborn WJ, Peyrin-Biroulet L: Efficacy of tumour necrosis factor antagonists on remission, colectomy and hospitalisations in ulcerative colitis: meta-analysis of placebo-controlled trials. Dig Liver Dis 2015;47:356-364.
29 Filippi J, Allen PB, Hébuterne X, Peyrin-Biroulet $\mathrm{L}$ : Does anti-TNF therapy reduce the requirement for surgery in ulcerative colitis? a systematic review. Curr Drug Targets 2011; 12:1440-1447.

30 Jeuring SF, Bours PH, Zeegers MP, Ambergen TW, van den Heuvel TR, Romberg-Camps $\mathrm{MJ}$, van Bodegraven AA, Oostenbrug LE, Breukink SO, Stassen LP, Hameeteman WH, Masclee AA, Jonkers DM, Pierik MJ: Disease outcome of ulcerative colitis in an era of changing treatment strategies: results from the Dutch population-based IBDSL cohort. J Crohns Colitis 2015;9:837-845.

31 Annese V, Duricova D, Gower-Rousseau C, Jess T, Langholz E: Impact of new treatments on hospitalisation, surgery, infection, and mortality in IBD: a focus paper by the epidemiology committee of ECCO. J Crohns Colitis $2016 ; 10: 216-225$.

32 Schreiber S, Panés J, Louis E, Holley D, Buch $\mathrm{M}$, Paridaens K: Perception gaps between patients with ulcerative colitis and healthcare professionals: an online survey. BMC Gastroenterol 2012;12:108

33 Schreiber S, Panés J, Louis E, Holley D, Buch $\mathrm{M}$, Paridaens K: National differences in ulcerative colitis experience and management among patients from five European countries and Canada: an online survey. J Crohns Colitis 2013;7:497-509.

34 Magro F, Portela F, Lago P, Deus J, Cotter J, Cremers I, Vieira A, Peixe P, Caldeira P, Lopes H, Gonçalves R, Reis J, Cravo M, Barros L, Ministro P, Lurdes Tavares M, Duarte A, Campos M, Carvalho L; Portuguese Study Group of IBD (GEDII); Association of Portuguese Patients with IBD (APDI): Inflammatory bowel disease: a patient's and caregiver's perspective. Dig Dis Sci 2009;54:2671-2679.

35 Waterman M, Knight J, Dinani A, Xu W, Stempak JM, Croitoru K, Nguyen GC, Cohen Z, McLeod RS, Greenberg GR, Steinhart AH, Silverberg MS: Predictors of outcome in ulcerative colitis. Inflamm Bowel Dis 2015;21: 2097-2105.

36 Kent A, Keshav S: Managing intractable proctitis and the problematic pouch. Dig Dis 2014; 32:427-437.

37 Reinisch W, Sandborn WJ, Hommes DW, D’Haens G, Hanauer S, Schreiber S, Panaccione R, Fedorak RN, Tighe MB, Huang B, Kampman W, Lazar A, Thakkar R: Adalimumab for induction of clinical remission in moderately to severely active ulcerative colitis: results of a randomised controlled trial. Gut 2011;60:780-787.

38 Isaacs KL: How rapidly should remission be achieved? Dig Dis 2010;28:548-555.

39 Sands BE: The risks and benefits of early immunosuppression and biological therapy. Dig Dis 2012;30(suppl 3):100-106

40 Lewis JD, Gelfand JM, Troxel AB, Forde KA, Newcomb C, Kim H, Margolis DJ, Strom BL: Immunosuppressant medications and mortality in inflammatory bowel disease. Am J Gastroenterol 2008;103:1428-1435. 
41 Bernstein CN, Ng SC, Lakatos PL, Moum B, Loftus EV Jr; Epidemiology and Natural History Task Force of the International Organization of the Study of Inflammatory Bowel Disease: A review of mortality and surgery in ulcerative colitis: milestones of the seriousness of the disease. Inflamm Bowel Dis 2013; 19:2001-2010.

42 van Bodegraven AA, Mulder C: Indications for 5-aminosalicylate in inflammatory bowel disease: Is the body of evidence complete? World J Gastroenterol 2006;12:6115-6123.

43 Probert C: Steroids and 5-aminosalicylic acids in moderate ulcerative colitis: addressing the dilemma. Therap Adv Gastroenterol 2013;6:33-38.

44 Loftus EV Jr, Davis KL, Wang CC, Dastani H, Luo A: Treatment patterns, complications, and disease relapse in a real-world population of patients with moderate-to-severe ulcerative colitis initiating immunomodulator therapy. Inflamm Bowel Dis 2014;20:1361-1367.

45 Armuzzi A, Pugliese D, Danese S, Rizzo G, Felice C, Marzo M, Andrisani G, Fiorino G, Sociale O, Papa A, De Vitis I, Rapaccini GL, Guidi L: Infliximab in steroid-dependent ulcerative colitis: effectiveness and predictors of clinical and endoscopic remission. Inflamm Bowel Dis 2013;19:1065-1072.

46 Baki E, Zwickel P, Zawierucha A, Ehehalt R, Gotthardt D, Stremmel W, Gauss A: Real-life outcome of anti-tumor necrosis factor $\alpha$ in the ambulatory treatment of ulcerative colitis. World J Gastroenterol 2015;21:3282-3290.

47 Stidham RW, Lee TC, Higgins PD, Deshpande AR, Sussman DA, Singal AG, Elmunzer BJ, Saini SD, Vijan S, Waljee AK: Systematic review with network meta-analysis: the efficacy of anti-tumour necrosis factor-alpha agents for the treatment of ulcerative colitis. Aliment Pharmacol Ther 2014;39:660-671.

48 Allez M, Karmiris K, Louis E, Van Assche G, Ben-Horin S, Klein A, Van der Woude J, Baert F, Eliakim R, Katsanos K, Brynskov J, Steinwurz F, Danese S, Vermeire S, Teillaud JL, Lémann M, Chowers Y: Report of the ECCO pathogenesis workshop on anti-TNF therapy failures in inflammatory bowel diseases: definitions, frequency and pharmacological aspects. J Crohns Colitis 2010;4:355-366.

49 Kawalec P, Mikrut A, Łopuch S: Systematic review of the effectiveness of biological therapy for active moderate to severe ulcerative colitis. J Gastroenterol Hepatol 2014;29: $1159-1170$

50 Colombel JF, Sands BE, Rutgeerts P, Sandborn W, Danese S, D'Haens G, Panaccione R, Loftus EV Jr, Sankoh S, Fox I, Parikh A, Milch C, Abhyankar B, Feagan BG: The safety of vedolizumab for ulcerative colitis and Crohn's disease. Gut 2017;66:839-851.

51 Danese S, Vuitton L, Peyrin-Biroulet L: Biologic agents for IBD: practical insights. Nat Rev Gastroenterol Hepatol 2015;12:537-545.

52 Hodgkins P, Swinburn P, Solomon D, Yen L, Dewilde S, Lloyd A: Patient preferences for first-line oral treatment for mild-to-moderate ulcerative colitis: a discrete-choice experiment. Patient 2012;5:33-44.

53 Bernal I, Domènech E, Garcia-Planella E, Marín L, Mañosa M, Navarro M, Cabré E, Gassull MA: Medication-taking behavior in a cohort of patients with inflammatory bowel disease. Dig Dis Sci 2006;51:2165-2169.

54 Hawthorne AB, Stenson R, Gillespie D, Swarbrick ET, Dhar A, Kapur KC, Hood K, Probert CS: One-year investigator-blind randomized multicenter trial comparing Asacol $2.4 \mathrm{~g}$ once daily with $800 \mathrm{mg}$ three times daily for maintenance of remission in ulcerative colitis. Inflamm Bowel Dis 2012;18:1885-1893.

55 Lopez A, Billioud V, Peyrin-Biroulet C, PeyrinBiroulet L: Adherence to anti-TNF therapy in inflammatory bowel diseases: a systematic review. Inflamm Bowel Dis 2013;19:1528-1533.

56 Engel MA, Neurath MF: New pathophysiological insights and modern treatment of IBD. J Gastroenterol 2010;45:571-583.

57 Peyrin-Biroulet L, Van Assche G, Sturm A, Gisbert JP, Gaya DR, Bokemeyer B, Mantzaris GJ, Armuzzi A, Sebastian S, Lara N, Lynam M, Rojas-Farreras S, Fan T, Ding Q, Black CM, Kachroo S: Treatment satisfaction, preferences and perception gaps between patients and physicians in the ulcerative colitis CARES study: a real world-based study. Dig Liver Dis 2016;48:601-607.

58 Vavricka SR, Bentele N, Scharl M, Rogler G, Zeitz J, Frei P, Straumann A, Binek J, Schoepfer AM, Fried M; Swiss IBDnet and Swiss IBD Cohort Study Group: Systematic assessment of factors influencing preferences of Crohn's disease patients in selecting an anti-tumor necrosis factor agent (CHOOSE TNF TRIAL). Inflamm Bowel Dis 2012;18:1523-1530.

59 Buisson A, Seigne AL, D'huart MC, Bigard MA, Peyrin-Biroulet L: The extra burden of infliximab infusions in inflammatory bowel disease. Inflamm Bowel Dis 2013;19:2464-2467.

60 Olivera P, Danese S, Peyrin-Biroulet L: Next generation of small molecules in inflammatory bowel disease. Gut 2017;66:199-209.

61 Colombel JF, Sandborn WJ, Reinisch W, Mantzaris GJ, Kornbluth A, Rachmilewitz D, Lichtiger S, D'Haens G, Diamond RH, Broussard DL, Tang KL, van der Woude CJ, Rutgeerts P; SONIC Study Group: Infliximab, azathioprine, or combination therapy for Crohn's disease. N Engl J Med 2010;362:1383-1395.

62 Kiss LS, Lakatos PL: Natural history of ulcerative colitis: current knowledge. Curr Drug Targets 2011;12:1390-1395.

63 Eriksson C, Rundquist S, Cao Y, Montgomery S, Halfvarson J: Impact of thiopurines on the natural history and surgical outcome of ulcerative colitis: a cohort study. Gut 2018, Epub ahead of print.

64 Ordás I, Eckmann L, Talamini M, Baumgart DC, Sandborn WJ: Ulcerative colitis. Lancet 2012;380:1606-1619.

65 Hanauer SB: Review article: evolving concepts in treatment and disease modification in ulcerative colitis. Aliment Pharmacol Ther 2008;27(suppl 1):15-21.
66 Peyrin-Biroulet L: Disease-modifying antiinflammatory bowel disease drugs(DMAIDs): the missing term in the literature. Am J Gastroenterol 2013;108:859-860.

67 Rutter MD, Saunders BP, Wilkinson KH, Rumbles S, Schofield G, Kamm MA, Williams $\mathrm{CB}$, Price AB, Talbot IC, Forbes A: Cancer surveillance in longstanding ulcerative colitis: endoscopic appearances help predict cancer risk. Gut 2004;53:1813-1816.

68 Peyrin-Biroulet L, Bressenot A, Kampman W: Histologic remission: the ultimate therapeutic goal in ulcerative colitis? Clin Gastroenterol Hepatol 2014;12:929-934.

69 Pittet V, Maillard MH, Lauvergeon S, Timmer M, Michetti P, Froehlich F, Burnand B, Vader JP, Mottet C: Acceptance of inflammatory bowel disease treatment recommendations based on appropriateness ratings: do practicing gastroenterologists agree with experts? J Crohns Colitis 2015;9:132-139.

70 Spiegel BM, Ho W, Esrailian E, Targan S, Higgins PD, Siegel CA, Dubinsky M, Melmed GY: Controversies in ulcerative colitis: a survey comparing decision making of experts versus community gastroenterologists. Clin Gastroenterol Hepatol 2009;7:168-174.

71 Florholmen J, Fries W: Candidate mucosal and surrogate biomarkers of inflammatory bowel disease in the era of new technology. Scand J Gastroenterol 2011;46:1407-1417.

72 Rogler G, Biedermann L: Clinical utility of biomarkers in IBD. Curr Gastroenterol Rep 2015;17:26.

73 Magro F, Lopes J, Borralho P, Lopes S, Coelho R, Cotter J, Castro FD, Sousa HT, Salgado M, Andrade P, Vieira AI, Figueiredo P, Caldeira P, Sousa A, Duarte MA, Ávila F, Silva J, Moleiro J, Mendes S, Giestas S, Ministro P, Sousa P, Gonçalves R, Gonçalves B, Oliveira A, Rosa I, Rodrigues M, Chagas C, Dias CC, Afonso J, Geboes K, Carneiro F; Portuguese IBD Study Group (GEDII): Comparison of different histological indexes in the assessment of UC activity and their accuracy regarding endoscopic outcomes and faecal calprotectin levels. Gut 2018, Epub ahead of print.

74 Magnusson MK, Strid H, Isaksson S, Bajor A, Lasson A, Ung KA, Öhman L: Cultured blood $\mathrm{T}$-cell responses predict anti-TNF therapy response in patients with ulcerative colitis. Aliment Pharmacol Ther 2015;41:1149-1161.

75 European Crohn's and Colitis Organisation eguide. https://www.ecco-ibd.eu/index.php/ publications/ecco-guidelines-science/published-ecco-guidelines.html. (accessed July 2017)

76 Harbord M, Eliakim R, Bettenworth D, Karmiris K, Katsanos K, Kopylov U, Kucharzik T, Molnár T, Raine T, Sebastian S, de Sousa HT, Dignass A, Carbonnel F; European Crohn's and Colitis Organisation [ECCO]: Third European evidence-based consensus on Diagnosis and management of ulcerative colitis. Part 2: current management. J Crohns Colitis 2017;11: 769-784. 
77 Bressler B, Marshall JK, Bernstein CN, Bitton A, Jones J, Leontiadis GI, Panaccione R, Steinhart AH, Tse F, Feagan B; Toronto Ulcerative Colitis Consensus Group: Clinical practice guidelines for the medical management of nonhospitalized ulcerative colitis: the toronto consensus. Gastroenterology 2015;148:1035-1058.

78 Bodger K, Ormerod C, Shackcloth D, Harrison M; IBD Control Collaborative: Development and validation of a rapid, generic measure of disease control from the patient's perspective: the IBD-Control questionnaire. Gut 2014;63:1092-1102.

79 Vasudevan A, Arachchi A, van Langenberg DR: Assessing patient satisfaction in inflammatory bowel disease using the QUOTE-IBD survey: a small step for clinicians, a potentially large step for improving quality of care. J Crohns Colitis 2013;7:e367-e374.

80 Bojic D, Bodger K, Travis S: Patient reported outcome measures (PROMs) in inflammatory bowel disease: new data. J Crohns Colitis 2017;11(suppl 2):S576-S585.

81 Jairath V, Khanna R, Zou GY, Stitt L, Mosli M, Vandervoort MK, D'Haens G, Sandborn WJ, Feagan BG, Levesque BG: Development of interim patient-reported outcome measures for the assessment of ulcerative colitis disease activity in clinical trials. Aliment Pharmacol Ther 2015;42:1200-1210.

82 Nahon S, Lahmek P, Durance C, Olympie A, Lesgourgues B, Colombel JF, Gendre JP: Risk factors of anxiety and depression in inflammatory bowel disease. Inflamm Bowel Dis 2012;18:2086-2091.

83 Villoria A, García V, Dosal A, Moreno L, Montserrat A, Figuerola A, Horta D, Calvet X,
Ramírez-Lázaro MJ: Fatigue in out-patients with inflammatory bowel disease: prevalence and predictive factors. PLoS One 2017; 12:e0181435.

84 Rubin DT, Dubinsky MC, Panaccione R, Siegel CA, Binion DG, Kane SV, Hopper J: The impact of ulcerative colitis on patients' lives compared to other chronic diseases: a patient survey. Dig Dis Sci 2010;55:1044-1052.

85 Lönnfors S, Vermeire S, Greco M, Hommes D, Bell C, Avedano L: IBD and health-related quality of life - discovering the true impact. J Crohns Colitis 2014;8:1281-1286.

86 Wilson B, Lonnfors S, Hommes DW, Vermeire V, Greco M, Bell C, Avedano L: A European Crohn's and ulcerative colitis patient life IMPACT survey. Poster P406 presented at ECCO 2012.

87 Kiebles JL, Doerfler B, Keefer L: Preliminary evidence supporting a framework of psychological adjustment to inflammatory bowel disease. Inflamm Bowel Dis 2010;16:16851695.

88 Sajadinejad MS, Asgari K, Molavi H, Kalantari M, Adibi P: Psychological issues in inflammatory bowel disease: an overview. Gastroenterol Res Pract 2012;2012:106502.

89 van Assche G, Peyrin-Biroulet L, Sturm A, Gisbert JP, Gaya DR, Bokemeyer B, Mantzaris GJ, Armuzzi A, Sebastian S, Lara N, Lynam M, Rojas-Farreras S, Fan T, Ding Q, Black CM, Kachroo S: Burden of disease and patient-reported outcomes in patients with moderate to severe ulcerative colitis in the last 12 months - multicenter European cohort study. Dig Liver Dis 2016;48:592600 .
90 Baars JE, Markus T, Kuipers EJ, van der Woude CJ: Patients' preferences regarding shared decision-making in the treatment of inflammatory bowel disease: results from a patient-empowerment study. Digestion 2010;81:113-119.

91 Elkjaer M, Shuhaibar M, Burisch J, Bailey Y, Scherfig H, Laugesen B, Avnstrøm S, Langholz E, O’Morain C, Lynge E, Munkholm P: E-health empowers patients with ulcerative colitis: a randomised controlled trial of the web-guided 'constant-care' approach. Gut 2010;59:1652-1661.

92 Rogler G, Biedermann L: Clinical utility of biomarkers in IBD. Curr Gastroenterol Rep 2015;17:26.

93 Tanaka M, Kawakami A, Iwao Y, Fukushima $\mathrm{T}$, Yamamoto-Mitani N: Coping strategies for possible flare-ups and their perceived effectiveness in patients with inflammatory bowel disease. Gastroenterol Nurs 2016;39:42-47.

94 Boye B, Lundin KE, Jantschek G, Leganger S, Mokleby K, Tangen T, Jantschek I, Pripp AH, Woiniusz S, Dahlstroem A, Rivenes AC, Benninghoven D, Hausken T, Roseth A, Kunzendorf S, Wilhelmsen I, Sharpe M, Blomhoff S, Malt UF, Jahnsen J: INSPIRE Study: Does stress management improve the course of inflammatory bowel disease and disease-specific quality of life in distressed patients with ulcerative colitis or crohn's disease? a randomized controlled trial. Inflamm Bowel Dis 2011; 17:1863-1873.

95 Gisbert JP, Linares PM, McNicholl AG, Maté J, Gomollón F: Meta-analysis: the efficacy of azathioprine and mercaptopurine in ulcerative colitis. Aliment Pharmacol Ther 2009; 30:126-137. 